Article

\title{
Preparation of Poly(ethylene glycol)@Polyurea Microcapsules Using Oil/Oil Emulsions and Their Application as Microreactors
}

\author{
Ahmad Zarour, Suheir Omar and Raed Abu-Reziq *(D) \\ Casali Center of Applied Chemistry and The Center for Nanoscience and Nanotechnology, Institute of Chemistry, \\ The Hebrew University of Jerusalem, Jerusalem 9190401, Israel; ahmad.zarour@mail.huji.ac.il (A.Z.); \\ suheir.omar@mail.huji.ac.il (S.O.) \\ * Correspondence: raed.abu-reziq@mail.huji.ac.il; Tel.: +972-2-6586097; Fax: +972-2-6585469
}

check for

updates

Citation: Zarour, A.; Omar, S.; Abu-Reziq, R. Preparation of Poly(ethylene glycol)@Polyurea Microcapsules Using Oil/Oil Emulsions and Their Application as Microreactors. Polymers 2021, 13, 2566 https://doi.org/10.3390/ polym13152566

Academic Editor: Eduardo Guzmán

Received: 14 July 2021

Accepted: 29 July 2021

Published: 31 July 2021

Publisher's Note: MDPI stays neutral with regard to jurisdictional claims in published maps and institutional affiliations.

Copyright: (c) 2021 by the authors. Licensee MDPI, Basel, Switzerland. This article is an open access article distributed under the terms and conditions of the Creative Commons Attribution (CC BY) license (https:/ / creativecommons.org/licenses/by/ $4.0 /)$.

\begin{abstract}
The development process of catalytic core/shell microreactors, possessing a poly(ethylene glycol) (PEG) core and a polyurea (PU) shell, by implementing an emulsion-templated non-aqueous encapsulation method, is presented. The microreactors' fabrication process begins with an emulsification process utilizing an oil-in-oil (o/o) emulsion of PEG-in-heptane, stabilized by a polymeric surfactant. Next, a reaction between a poly(ethylene imine) (PEI) and a toluene-2,4-diisocyanate (TDI) takes place at the boundary of the emulsion droplets, resulting in the creation of a PU shell through an interfacial polymerization (IFP) process. The microreactors were loaded with palladium nanoparticles (NPs) and were utilized for the hydrogenation of alkenes and alkynes. Importantly, it was found that PEG has a positive effect on the catalytic performance of the developed microreactors. Interestingly, besides being an efficient green reaction medium, PEG plays two crucial roles: first, it reduces the palladium ions to palladium NPs; thus, it avoids the unnecessary use of additional reducing agents. Second, it stabilizes the palladium NPs and prevents their aggregation, allowing the formation of highly reactive palladium NPs. Strikingly, in one sense, the suggested system affords highly reactive semi-homogeneous catalysis, whereas in another sense, it enables the facile, rapid, and inexpensive recovery of the catalytic microreactor by simple centrifugation. The durable microreactors exhibit excellent activity and were recycled nine times without any loss in their reactivity.
\end{abstract}

Keywords: non-aqueous interfacial polymerization; polyurea microcapsules; poly(ethylene glycol); oil-in-oil emulsions; hydrogenation

\section{Introduction}

The pursuit of a sustainable future has become the driving force for today's science, where pioneering approaches toward greener processes are continually being developed. In this regard, the design of efficient and facile catalytic systems is highly desired [1,2]. Although the homogeneous route of catalysis is endowed with high reactivity and selectivity $[3,4]$, most of the industrial catalytic processes rely on the heterogeneous counterpart owing to significant recovery and cost concerns [5,6]. Many efforts have been devoted to bridging the gap between the two routes and to utilizing their advantages; in this regard, numerous methods have been developed. Among others, this includes the use of Pickering emulsion systems [7,8], anchored single-atom catalysts [9], mesoscale nanostructures [10], and tunable solvents [11].

The use of metal nanoparticles constitutes another powerful tool for combining the advantages of both disciplines because of metal nanoparticles' high surface area [12,13]. However, despite their great reactivity and selectivity, metal nanoparticles require additional immobilization techniques to avoid their aggregation, and usually involve the use of different supports to enable catalyst recovery. The uses of organic polymer supports [14-16], dendrimers [17-19], supported ionic liquid phase (SILP) catalysts [20-22], 
magnetic nanoparticles (MNPs) [23-25], and inorganic supports [26-28] are just a few examples of many immobilization techniques available for metal nanoparticles. However, along with leaching problems, these methods generally involve multiple synthetic steps and pre-functionalization processes, which make the development of new catalysts difficult, expensive, and cumbersome. Moreover, generally, their reactivity and selectivity are less efficient in comparison with the pure homogeneous catalysts.

Recently, catalysis within microenvironmental entities, called in brief microreactors, has been proven to be efficient at least as the pure homogeneous route. The remarkably enhanced catalytic performance refers to the local high concentrations of reagents within the dispersed microreactors, a fact that dramatically increases the reaction rate constants [29-34]. Accordingly, microcapsules (MCs) might serve as a useful tool for inducing such microenvironmental catalytic conditions [35-38]. Microencapsulation involves the process of confining various types of ingredients for diverse purposes, such as the controlled release of pesticides in agriculture [39-41], the release of drugs in pharmaceutical applications [42-44], the masking of odors and tastes in the food industry [45-47], and the protection and recycling of catalysts [48-52].

Interfacial polymerization (IFP) is a well-known chemical method for preparing MCs [53-56]. This process is based on a polycondensation reaction between two highly reactive monomers; it takes place at the boundary of two immiscible phases, and each phase contains one of the two monomers. Polyurea (PU) is the most common polymer prepared via IFP for the synthesis of MCs; it has been thoroughly investigated and applied in different fields [57-62]. PUs are generated from the reaction between amine and isocyanate monomers. These MCs are considered valuable owing to their unique features, such as low $\mathrm{Tg}$, rubbery characteristics, as well as their chemical [61] and mechanical [60] stability and biocompatibility, [63] which make them an ideal material for holding liquid in their core even for in vitro applications. In addition to the encapsulation of ionic liquids, which was demonstrated by our group [64], phase change materials [65] and more common organic solvents, such as xylene [66], were found to serve as an efficient platform for implementing PU MCs. The encapsulation process in the latter examples was preceded by an oil-inwater $(\mathrm{o} / \mathrm{w})$ emulsification process. Furthermore, water-in-oil (w/o) emulsion-templated PU MCs have been reported as well [67]. However, these two emulsification strategies $(\mathrm{o} / \mathrm{w}$ and $\mathrm{w} / \mathrm{o})$ cannot provide an adequate solution in the case of moisture-sensitive ingredients, including catalysts. Thus, the development of a non-aqueous process, such as the use of oil-in-oil (o/o) emulsions, is of the utmost importance [68-72]. Although PU MCs and o/o emulsions themselves are well-established topics, their combination has barely been studied [73-77]. In addition, palladium NPs have been successfully supported on different catalytic systems, including magnetic carbon-coated cobalt nanobeads [78], silicon nanowire arrays [79], and cotton and filter paper [80], and were applied in the hydrogenation of alkenes. Moreover, palladium NPs were successfully encapsulated within PU MCs based on oil-in-water [81-83] and water-in-oil [84] emulsions.

Herein, we present the first palladium-based PU microreactor prepared via a nonaqueous process that utilizes an o/o emulsion. A low-molecular-weight poly (ethylene glycol) (PEG) was successfully encapsulated, for the first time, within a PU shell. PEG represents a green reaction medium owing to its low vapor pressure and it is considered as a GRAS (generally recognized as safe) material $[85,86]$. In addition to its acting as a green medium for organic transformations, PEG was also found to play two additional roles that have a direct positive impact on the catalytic performance. First, it acts as a good stabilizing agent for palladium NPs, which is in line with the results obtained in other works [87-90]. Thus, it prevents the aggregation of palladium NPs and increases their reactivity. Second, it acts as a reducing agent, avoiding the need for additional reducing agents to activate the palladium NPs. Recently, PEG-based microcapsules were developed and applied for energy storage [91,92] or drug formulation [93-95] and for creating unique multilayer polymeric shells with complex structures [96]. 


\section{Materials and Methods}

\subsection{Materials}

The organic solvents heptane, toluene, xylene, and cyclohexane were purchased from Romical, along with chemicals and laboratory equipment. Poly(1-vinylpyrrolidone)-graft(1-hexadecene) co-polymer (containing $80 \%$ by weight of $C_{16} \alpha$-olefin and $20 \%$ by weight of polymerized vinylpyrrolidone) (Agrimer AL-22) was purchased from International Specialty Products (ISP). Bis-poly(ethylene glycol)/poly(propylene glycol)-14/14 dimethicone (ABIL EM 97) was purchased from Evonik. Poly(ethylene glycol) 200, sodium tetrachloropalladate $\left(\mathrm{Na}_{2} \mathrm{PdCl}_{4}\right)$, dioctyl sulfosuccinate sodium salt (AOT), sorbitan monooleate (span 80), poly (ethylene glycol) oleyl ether (brij 92v), branched poly(ethylene amine) 800, $2,2^{\prime}$ (ethylenedioxy)bis(ethylamine), hexamethylenediamine (HMDA), and diethylenetriamine (DETA) were purchased from Sigma Aldrich-Merck. Polymethylene polyphenyl isocyanate (PAPI 27) was contributed by FMC Corporation. Toluene-2,4-diisocyanate (TDI) was purchased from Acros Organics. All substrates were purchased either from Alfa Aesar (Tewksbury, MA, USA) or Sigma Aldrich-Merck (Budapest, Hungary).

\subsection{Instrumentation}

The o/o emulsion containing $0.01 \%$ Rhodamine B in PEG200 was analyzed by a fluorescence microscope (Carl Zeiss, Axio Vision, Mátészalka, Hungary). The catalytic microcapsules were initially examined using a high-resolution scanning electron microscope (HR SEM) Sirion from FEI equipped with a Shottky-type field emission source and a secondary electron (SE) detector at $5 \mathrm{kV}$. Focused ion beam (FIB-SEM), using a FEI Helios nanolab 460S1 instrument, was used to investigate the inner and outer morphology of the microcapsules and to evaluate whether core-shell or matrix structures were obtained. Moreover, it was utilized for the mapping and EDXS (energy dispersive X-ray spectroscopy) analyses. 1H-NMR measurements were performed using a Bruker DRX-400 spectrometer to determine conversion and selectivity. Emulsifications were performed using the Kinematica Polytron homogenizer PT-6100 equipped with dispersing aggregate 3030/4EC. IR was recorded with $\mathrm{KBr}$ pellets at room temperature in transmission mode on a PerkinElmer 65 FTIR spectrometer to determine the chemical composition of the microcapsules. In addition, thermogravimetric analysis (TGA) was performed using a Mettler Toledo TG 50 analyzer at a temperature range of $25-700^{\circ} \mathrm{C}$ and at a heating rate of $10^{\circ} \mathrm{C} \mathrm{min}-1$ under $\mathrm{N}_{2}$ atmosphere. Scanning transmission electron microscopy (STEM) and electron diffraction spectroscopy (EDS) were performed with (S)TEM Tecnai F20 G2 (FEI Company, Hillsboro, OR, USA) operated at $200 \mathrm{kV}$.

\subsection{The Procedure for Preparing the $P d_{N P S} / P E G_{200}$ Polar Phase}

In a vial of $10 \mathrm{~mL}, 100 \mathrm{mg}(0.287 \mathrm{mmol})$ of $\mathrm{Na}_{2} \mathrm{PdCl}_{4}$ was dissolved and sonicated in $4.66 \mathrm{~g}$ of $\mathrm{PEG}_{200}$ for one hour. At this stage, the mixture's color changes from light red to dark red and then to black, indicating that the palladium was reduced. Then, $0.34 \mathrm{~g}$ of an amine was added and the mixture was allowed to sonicate for one more hour.

\subsection{General Procedure for Preparing the $P d_{N P S} / P E G_{200} @ P U$ Microreactors}

In a $100 \mathrm{~mL}$ beaker, $2.00 \mathrm{~g}$ of surfactant was dissolved in $13.40 \mathrm{~g}$ of heptane. The solution was homogenized at $10,000 \mathrm{rpm}$ for $30 \mathrm{~s}$. Then, the $\mathrm{Pd}_{\mathrm{NPs}} / \mathrm{PEG}_{200}$ polar phase was added and the homogenization proceeded for another two minutes. Afterward, a mixture of $0.6 \mathrm{~g}$ of an isocyanate dissolved in $4 \mathrm{~g}$ of xylene was added dropwise. The emulsion was allowed to stir at $500 \mathrm{rpm}$ on a stirring plate for $4 \mathrm{~h}$ at room temperature. The resulting catalytic microreactors were separated by centrifugation and washed three times with heptane. The $\mathrm{Pd}_{\mathrm{NPs}} / \mathrm{PEG}_{200} @ \mathrm{PU} \mathrm{MC}$ s were then dispersed in heptane until the weight of the whole dispersion was $20.00 \mathrm{~g}$. 


\subsection{General Procedure for the Hydrogenation Reaction}

In a $25 \mathrm{~mL}$ glass-lined autoclave equipped with a magnetic stirring bar, $1 \mathrm{~g}$ of the catalytic dispersion $(0.047 \mathrm{mmol}$ of Pd per $1 \mathrm{~g}$ of dispersion) was added to $2 \mathrm{~mL}$ of heptane. Then, a suitable amount of substrate was added relative to the substrate/catalyst (S/C) ratio. The autoclave was purged three times with $\mathrm{H}_{2}$ and then pressurized to $100 \mathrm{psi}$ of $\mathrm{H}_{2}$. The reactions were carried out at room temperature for $2.5 \mathrm{~h}$. Finally, the MCs were separated from the reaction mixture by centrifugation, washed two times with heptane, redispersed in $3 \mathrm{~mL}$ of heptane, and then used for the next catalytic cycle. The reaction content was examined using ${ }^{1} \mathrm{H}-\mathrm{NMR}$ spectroscopy in order to determine the conversion and selectivity.

\section{Results and Discussion}

\subsection{Synthesis and Optimization of the PEG $200 @ P U M C s$}

The synthesis of the polyurea microcapsules (PU MCs) is based on an emulsiontemplated non-aqueous encapsulation process. The preparation procedure begins with an emulsification process consisting of two immiscible oil phases: (1) the polar dispersed phase consists of branched poly(ethylene imine $)_{800}\left(\mathrm{PEI}_{800}\right)$ and $\mathrm{Na}_{2} \mathrm{PdCl}_{4}$ dissolved in poly(ethylene glycol $)_{200}\left(\mathrm{PEG}_{200}\right)$, and the $\mathrm{PEG}_{200}$ rapidly reduces the palladium (II) ions to palladium (0) nanoparticles (NPs); and (2) a polar continuous phase of heptane containing the polymeric surfactant ABIL EM 90. Then, a toluene-2,4-diisocyanate (TDI) dissolved in xylene was slowly added while the homogenization process was running. Finally, an interfacial polymerization process at the boundary of the emulsion droplets between the PEI and the TDI is executed, leading to the creation of a PU MC possessing a core/shell structure owing to the insolubility of the PU in PEG (Scheme 1).

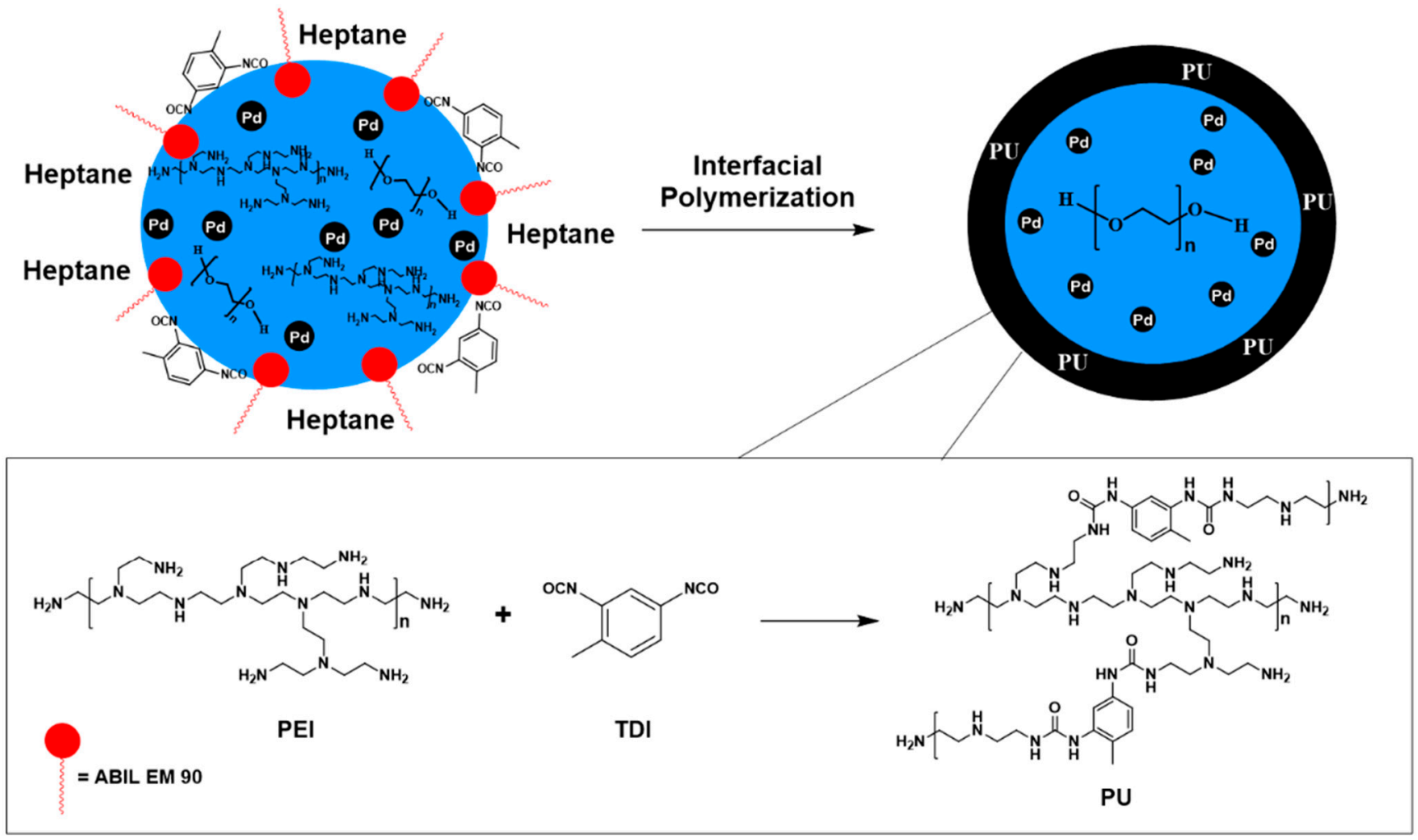

Scheme 1. Schematic illustration of the $\mathrm{Pd}_{\mathrm{NPs}_{\mathrm{s}}} / \mathrm{PEG}_{200} @ \mathrm{PU}$ preparation procedure.

The selection of these materials was determined after conducting a series of optimization experiments in which other continuous phases (cyclohexane and toluene), surfactants (Agrimer AL-22, AOT, span 80, and brij 92v), amines (2,2'(ethylenedioxy)bis(ethylamine), 
HMDA, and DETA) and isocyanate (PAPI 27) were examined. Briefly, excluding the polymeric surfactants, ABIL EM 90, and Agrimer AL-22 (Figure S1), none of the surfactants were able to stabilize the $\mathrm{o} / \mathrm{o}$ emulsion; the stabilization of such emulsions is not obvious and usually requires the involvement of multi-armed polymeric surfactants rather than small ones; the former settle irreversibly at the interface of the droplets, as their departure from the interface requires that all the surfactants' arms leave the interface concomitantly, which is statistically less possible. Moreover, whereas the interfacial polymerization of the PEI/TDI and DETA/TDI pairs fabricates MCs, the 2,2' (ethylenedioxy)bis(ethylamine)/PAPI 27 and HMDA/PAPI 27 pairs result in the formation of nanocapsules (Table S1). However, the latter two suffer from aggregation problems, whereas in the case of the DETA/TDI pair, the encapsulation of $\mathrm{PEG}_{200}$ is not attainable. In the case of cyclohexane only, the DETA/TDI pair affords MCs when Agrimer AL-22 was utilized as the emulsion stabilizer (Figure S2); however, as already mentioned, the encapsulation of $\mathrm{PEG}_{200}$ with this pair is not viable. For toluene, well-defined MCs were not obtained with either of the pairs.

\subsection{Characterization of the $P d_{N P s} / P E G_{200} @ P U M C s$}

First, the catalytic system was investigated before the penetration of the palladium. Scanning electron microscopy (SEM) was employed for determining the morphological structure of our system (Figure 1a,b). Smoothed spherical surfaces and some pressed capsules, caused by the high vacuum applied in this analysis, were obtained. As can be easily noted, a polydispersed system with sizes ranging from $200 \mathrm{~nm}$ to $15 \mu \mathrm{m}$ was formed, which is a typical feature of macroemulsion systems. The measurement of the size of the microcapsules dispersed in isopropyl alcohol by laser diffraction size analyzer indicated an average size of $12.48 \mu \mathrm{m}\left(\mathrm{d}_{0.5}=12.48\right.$ micron, Figure S3). Moreover, fluorescent microscopy images indicate the presence of the liquid $\mathrm{PEG}_{200}$, accompanied by $0.01 \mathrm{wt} . \%$ of Rhodamine B dye, within the PU MCs (Figure 1c,d).
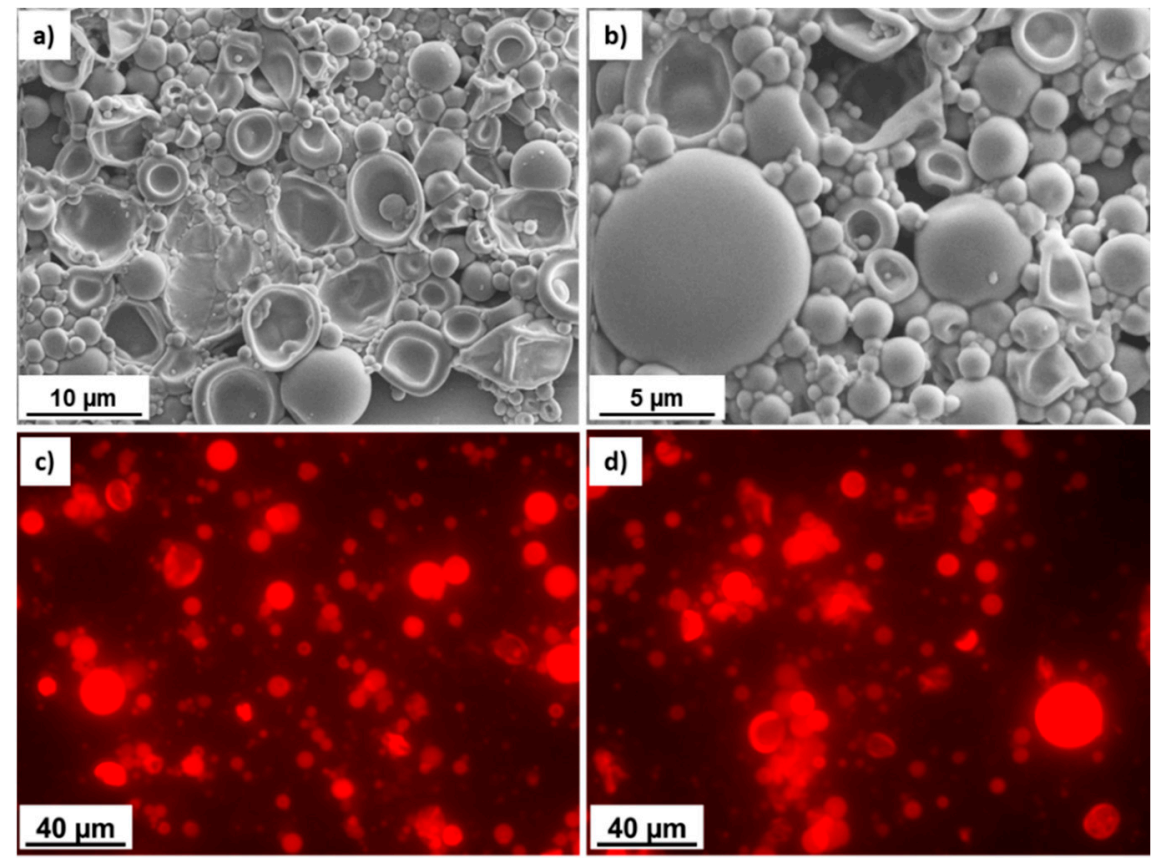

Figure 1. (a,b) Scanning electron microscopy (SEM) and (c,d) fluorescent microscopy images of $\mathrm{PEG}_{200} @ \mathrm{PU}$ microcapsules (MCs).

Thermogravimetric analysis (TGA) indicates the existence of two weight loss stages (Figure 2). The first weight loss is associated with the decomposition of the encapsulated $\mathrm{PEG}_{200}$. This weight loss occurs almost at the same range of temperatures at which pure $\mathrm{PEG}_{200}$ decomposes $\left(200-300{ }^{\circ} \mathrm{C}\right)$, and constitutes $85 \%$ of the sample's weight, which is in agreement with the calculated wt. $\%$ of $\mathrm{PEG}_{200}$ from the total amount of MCs (87\%). The 
second weight loss $(15 \%)$, centered at $400{ }^{\circ} \mathrm{C}$, apparently is associated with the thermal decomposition of the PU shell, which, according to the theoretical calculations, stands at $13 \%$. Moreover, the MCs are thermally stable up to $200{ }^{\circ} \mathrm{C}$; this makes them applicable even when elevated temperatures are needed.

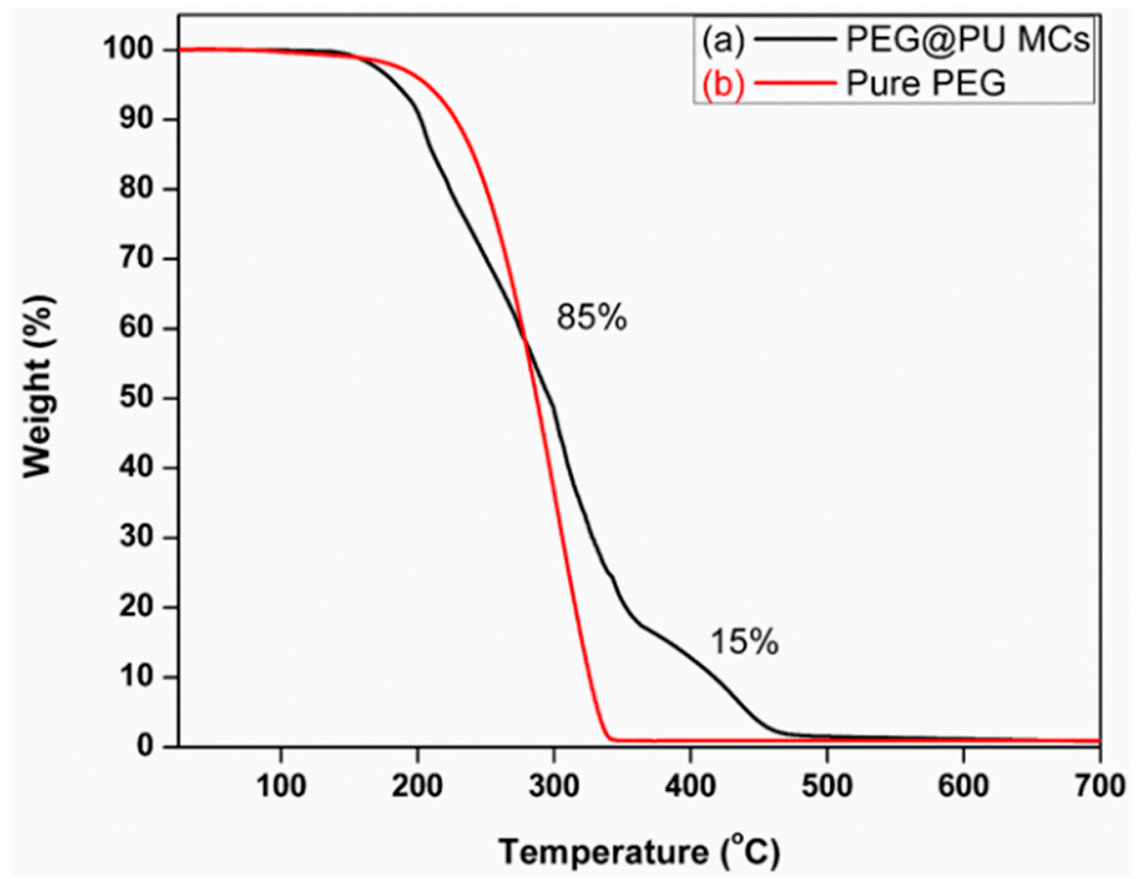

Figure 2. Thermogravimetric analysis (TGA) curves of (a) PEG $200 @ P U M C$ s and (b) pure PEG200.

Fourier-transform IR (FT-IR) was further employed to confirm the chemical composition in the system. The results presented in Figure 3 revealed that polyurea polymerization was achieved. The absence peak band at $\sim 2270 \mathrm{~cm}^{-1}$ confirms the total polymerization of the isocyanate monomer (TDI), which apparently reacted completely with the branched $\mathrm{PEI}_{800}$ to form the polyurea shell. The absorption bands at $846 \mathrm{~cm}^{-1}\left(\mathrm{CH}_{2}\right.$ rocking), $890 \mathrm{~cm}^{-1}$ (C-OH bending), $1100 \mathrm{~cm}^{-1}$ (C-O stretching), and $2870-2960 \mathrm{~cm}^{-1}$ refer to $\mathrm{PEG}_{200}$, whereas the wide absorption band from 3000 to $3700 \mathrm{~cm}^{-1}$ is attributed to the N-H and $\mathrm{O}-\mathrm{H}$ stretching vibrations of polyurea and PEG.

After confirming the feasibility for the formation of the MCs, they were loaded with palladium NPs and characterized by different methods. The focused ion beam (FIB-SEM) images indicate that the MCs maintain their morphology and their spherical structure after the penetration of the palladium (Figure $4 \mathrm{a}, \mathrm{b}$ ). Moreover, a cutting process confirms the existence of a core/shell structure with a shell thickness of $\sim 1 \mu \mathrm{m}$ (Figure $4 \mathrm{c}, \mathrm{d}$ ); however, the thickness varied, depending on the MC size. The presence of the carbon, nitrogen, and oxygen elements was further confirmed by conducting mapping and EDXS (energy dispersive X-ray spectroscopy) analyses, for the cut MC and the complete MCs (Figures S4 and S5).

However, although the EDXS analysis confirms the existence of palladium, the mapping measurement was not sensitive enough to detect the presence of palladium. In this regard, we carried out the mapping measurement in scanning transmission electron microscopy (STEM) mode (Figure 5a). Moreover, the figure reveals that the palladium NPs were successfully encapsulated within the MCs. The presence of palladium was also verified by EDXS analysis (Figure 5b). Besides the already known positive stabilization effect of the PEG [87-90], the very small palladium NPs are further stabilized by the nitrogen atoms of the branched $\mathrm{PEI}_{800}$ and by the microencapsulation process itself; the latter constructs a concrete barrier between the palladium NPs and constitutes a hurdle to the possibility of high constrictions of palladium NPs, which eventually will lead to aggregation processes and, subsequently, to a drop in the catalytic activity. 


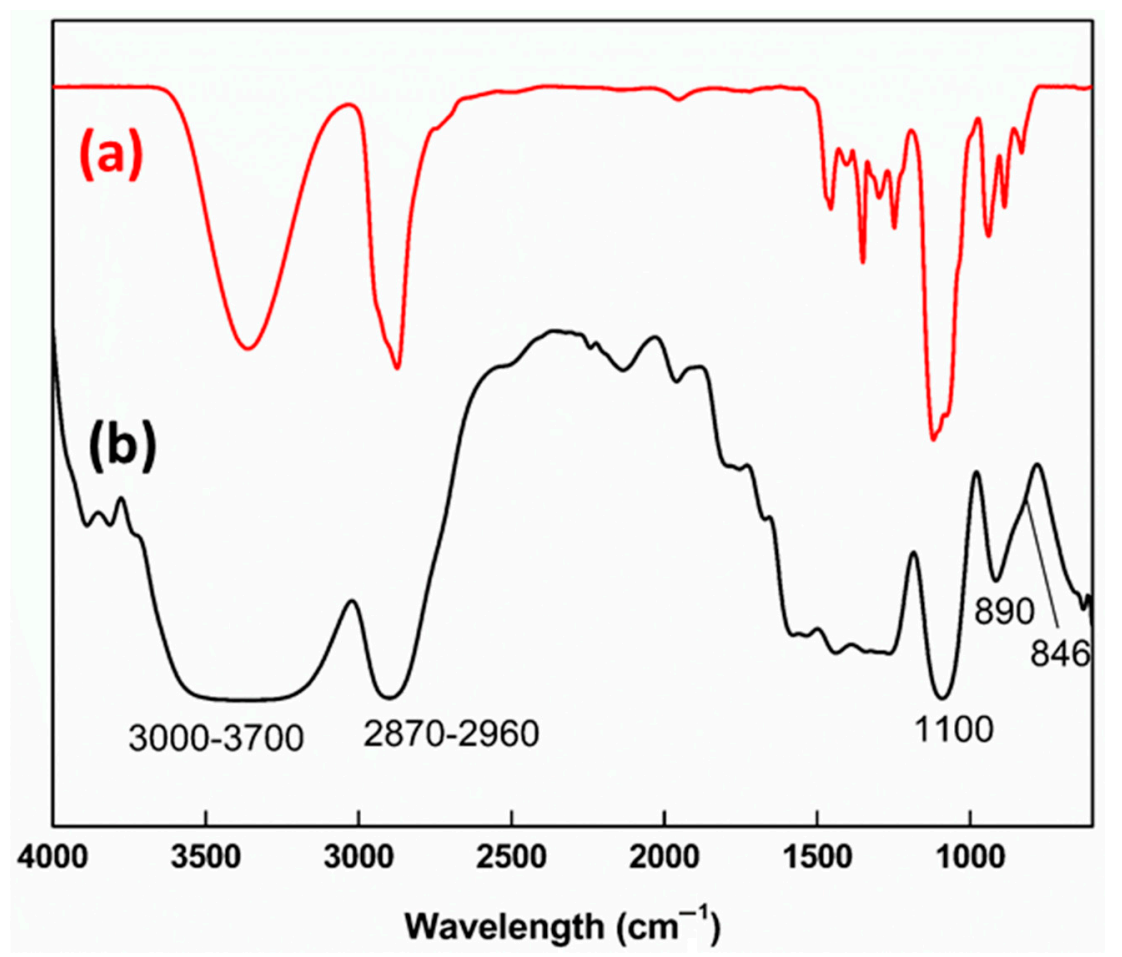

Figure 3. Fourier-transform IR (FT-IR) spectra of (a) pure PEG200 and (b) PEG $200 @ P U$ MCs.
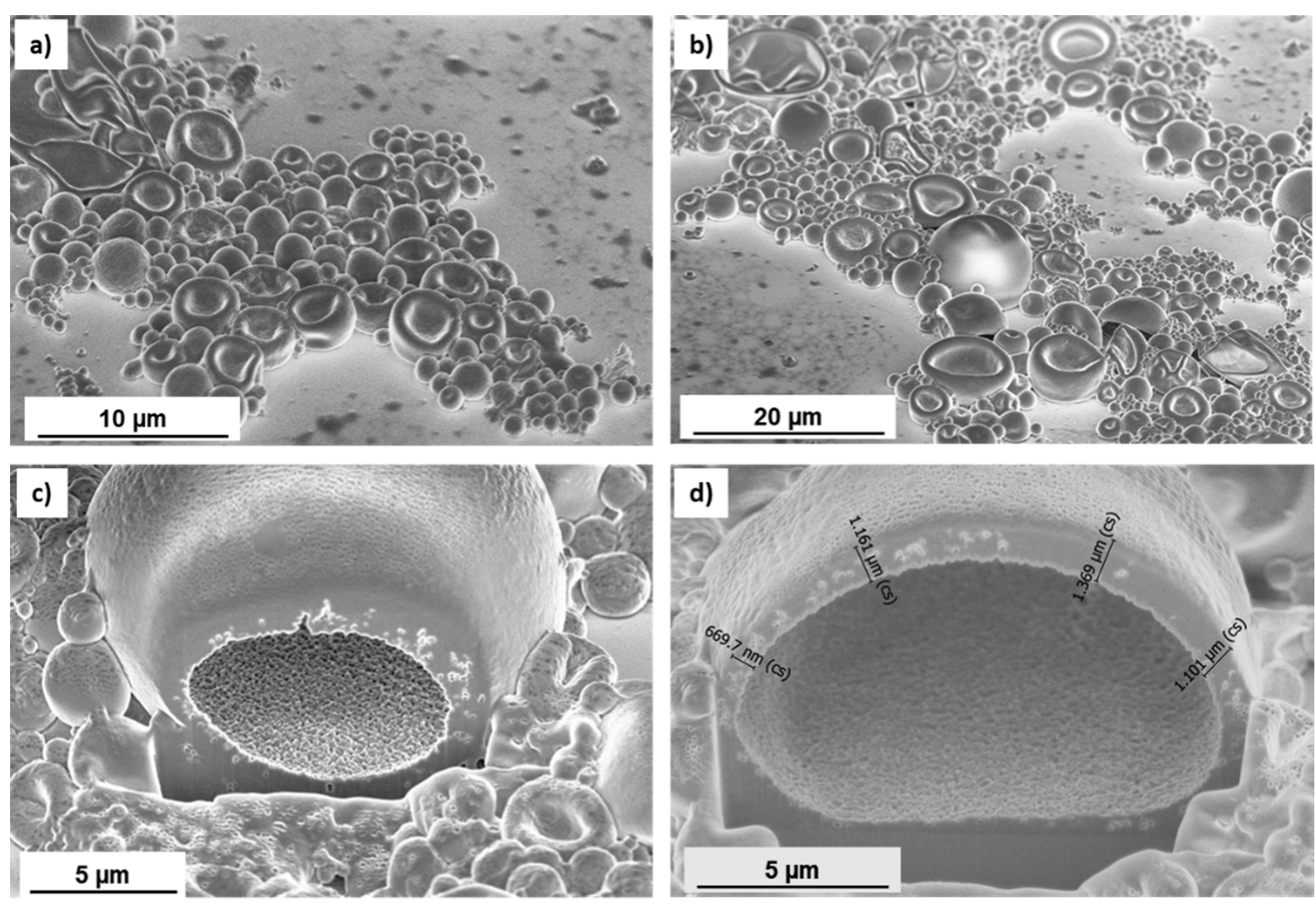

Figure 4. Focused ion beam (FIB)-SEM images of the PdNPs/PEG200@PU MCs before etching process (a,b) and after etching (c,d). 

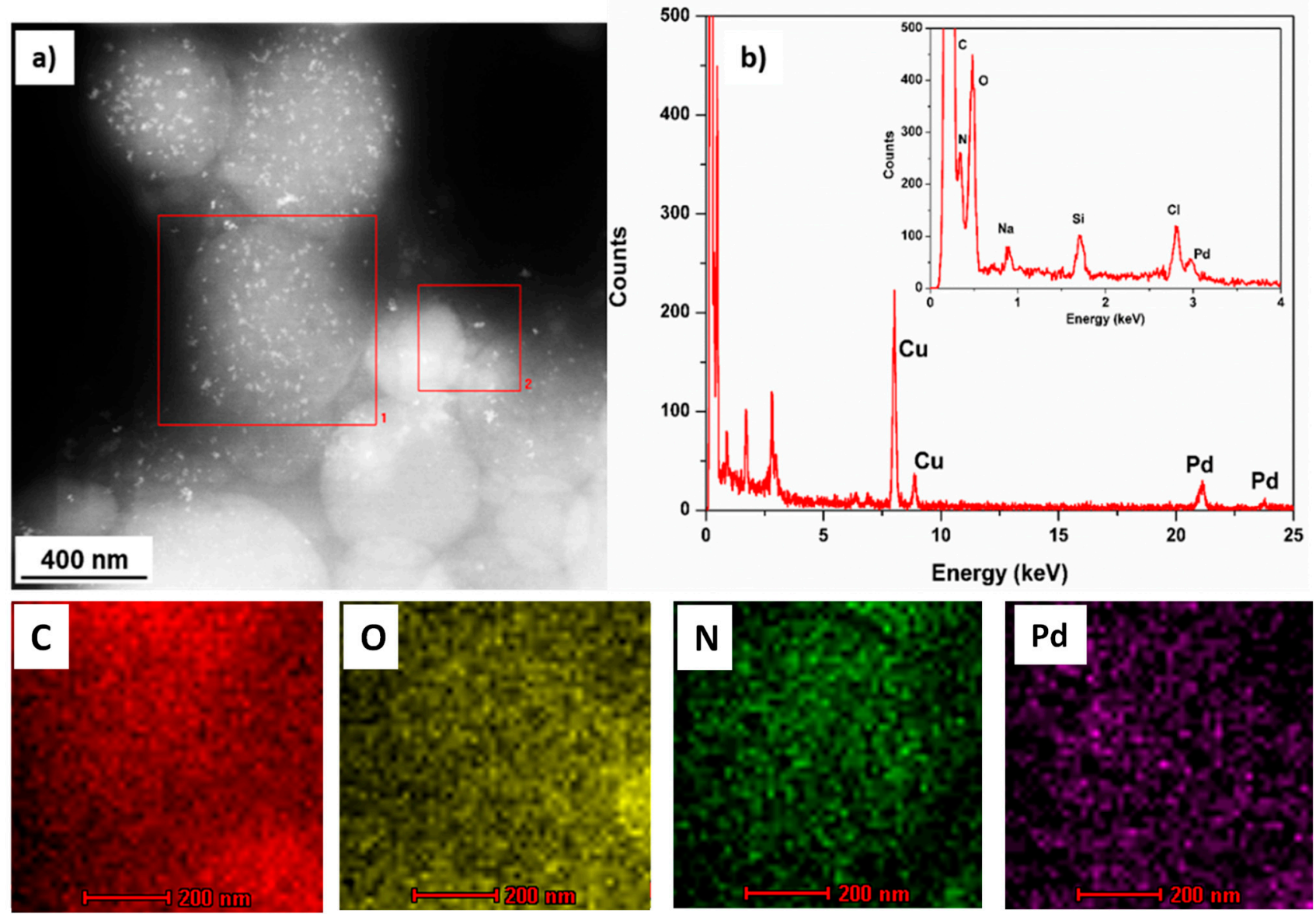

Figure 5. STEM mode applied for the (a) mapping and (b) energy dispersive X-ray spectroscopy (EDXS) analyses of the $\mathrm{Pd}_{\mathrm{NPs}} / \mathrm{PEG}_{200} @ \mathrm{PU} \mathrm{MCs}$.

\subsection{Evaluation of the Catalytic Performance}

The catalytic performance of the $\mathrm{Pd}_{\mathrm{NPs}} / \mathrm{PEG}_{200} @ \mathrm{PU}$ microreactor was tested in the hydrogenation of various alkenes and alkynes. As shown in Table 1, the catalyst exhibits highly desirable activity in the hydrogenation of alkenes. Fully saturated alkanes could be generated smoothly under mild conditions (Table 1, entries 1-6). The catalyst's activity was also tested in the hydrogenation of alkynes; aromatic terminal alkynes were fully converted to the corresponding fully hydrogenated products (Table 1, entries 7-9). Interestingly, parasubstrates, such as 4-vinylanisole and 4-methylstyrene, exhibit a slightly better catalytic performance compared with meta-substrates, such as 3-methylstyrene and 3-chlorostyrene. Nevertheless, such a finding requires further kinetic experiments and an in-depth investigative study of the microreactor structure's porosity. In addition, diphenylacetylene, which was also fully converted, exhibits exceptional behavioral patterns with a moderate selectivity of $61 \%$ towards the cis-stilbene and 39\% towards the fully hydrogenated bibenzyl. This partial selectivity could be attributed to the steric hindrance of the cis-stilbene formed initially, which can slow its hydrogenation within the Pd/PEG@polyurea microreactor (Table 1, entry 10). An excellent reactivity of our catalyst was also achieved when a substrate/catalyst ratio of 5000 was applied in the hydrogenation of styrene (Table 1 , entry 11).

Furthermore, the catalytic performance of the developed microreactor was compared with a completely homogeneous system. In this regard, the hydrogenation of styrene was used as a model reaction. Strikingly, the $\mathrm{Pd}_{\mathrm{NPs}} / \mathrm{PEG}_{200} @ \mathrm{PU}$ microreactor exhibits catalytic supremacy over the pure homogeneous catalyst under the same conditions; the homogeneous catalyst reached $28 \%$ in $\mathrm{PEG}_{200}$, whereas the microreactor reached $100 \%$ conversion. These results indicate that the PEG stabilization does not ensure high catalytic 
reactivity; however, performing the reaction within a microenvironmental entity guarantees a high local concentration of interactions between the catalyst and the substrates, leading to an improved catalytic performance and highly efficient processes.

Table 1. The catalytic performance of the $\mathrm{Pd}_{\mathrm{NPs}} / \mathrm{PEG}_{200} @ \mathrm{PU}$ microreactor in the hydrogenation reaction.

Entry Conversion (\%) ${ }^{\mathbf{a}}$

Reaction conditions: $0.2 \mathrm{~mol} \%$ of $\mathrm{Pd}$ (substrate/Pd ratio $=500), 2.5 \mathrm{~h}$, r.t., $100 \mathrm{psi}$ of $\mathrm{H}_{2} \cdot{ }^{a}$ Determined by ${ }^{1} \mathrm{HNMR} .{ }^{\mathrm{b}} 61 \%$ cis-stilbene and $39 \%$ bibenzyl. ${ }^{c} 0.02 \mathrm{~mol} \%$ of $\mathrm{Pd}$ (substrate/Pd ratio $=5000$ ).

Finally, the recyclability of our catalyst was examined. The catalyst was recycled nine times without showing any loss of its activity, as seen in Figure 6. The catalyst was easily separated by centrifugation, washed, and reused for the next cycle.

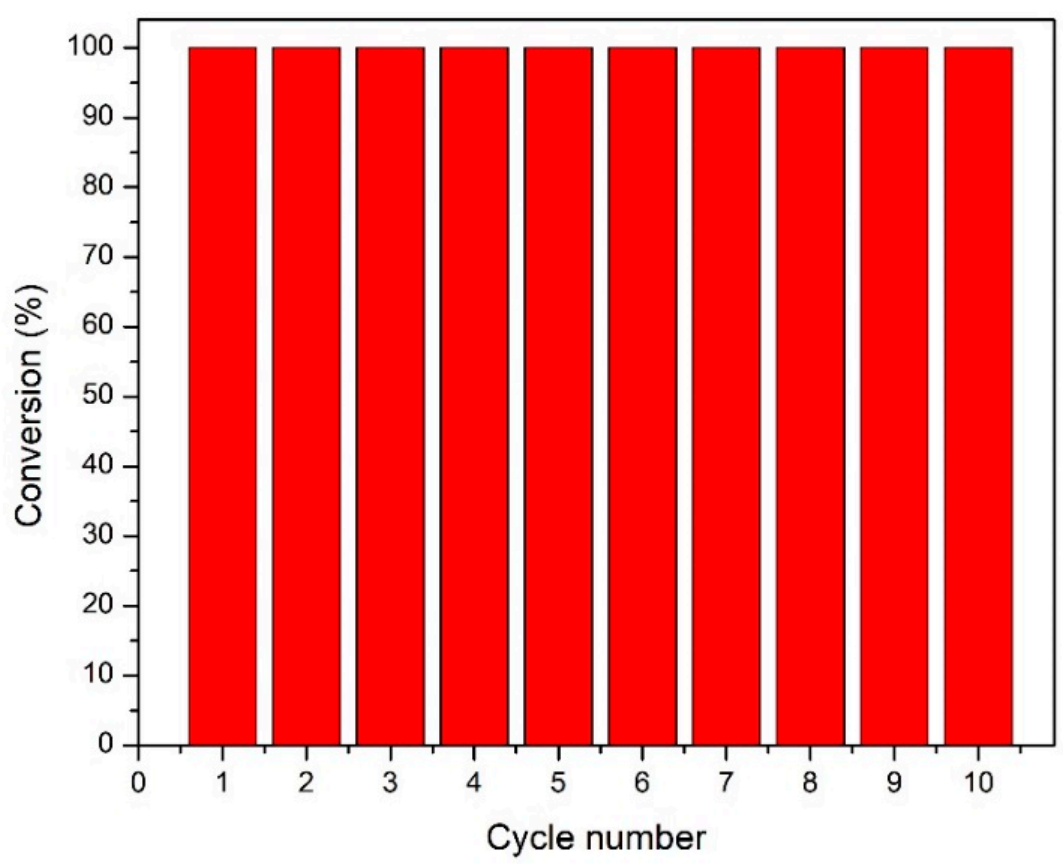

Figure 6. Recyclability of the $\mathrm{Pd}_{\mathrm{NPs}} / \mathrm{PEG}_{200} @ \mathrm{PU}$ microreactor in the hydrogenation reaction of styrene (reaction conditions: $0.2 \mathrm{~mol} \%$ of $\mathrm{Pd}$ (substrate/Pd ratio = 500), $2.5 \mathrm{~h}$, r.t., $100 \mathrm{psi} \mathrm{of} \mathrm{H}_{2}$ ). 


\section{Conclusions}

With our continuous intent to bridge the gap between the homogeneous and heterogeneous routes, highly reactive $\mathrm{Pd}_{\mathrm{NPs}} / \mathrm{PEG}_{200} @ \mathrm{PU}$ microreactors were successfully developed. The fabrication process is based on implementing an o/o emulsion-templated non-aqueous microencapsulation, through the interfacial polymerization of $\mathrm{PEI}_{800}$ and TDI. These microreactors were well characterized and utilized in the hydrogenation of aromatic alkenes and alkynes, exhibiting extraordinary reactivity. The catalytic supremacy results from the very small and efficient palladium NPs; such a stabilization is achievable owing to the presence of PEG, which, to the best of our knowledge, was not encapsulated previously within a PU shell, surely not by a non-aqueous route. Not less important is the existence of the microenvironmental entity, which allows high local concentrations of interactions between the catalyst and substrates. Finally, the robust PU shell maintains the spherical structure of the microreactor and enables its facile recovery and recyclability.

Supplementary Materials: The following are available online at https: / www.mdpi.com/article / 10.3390/polym13152566/s1, Figure S1: SEM images of PEG@PU microcapsules prepared using different surfactants; Table S1: PEG $_{200} @ P U$ microcapsules obtained using different amines and isocyanate monomers; Figure S2: SEM image of $\mathrm{PEG}_{200} @ \mathrm{PU}$ microcapsules obtained using $\mathrm{PEG}_{200^{-}}$ in-cyclohexane emulsions; Figure S3: FIB-SEM images of $\mathrm{Pd}_{\text {nano }} / \mathrm{PEG}_{200} @ \mathrm{PU}$ microcapsules.

Author Contributions: Conceptualization, R.A.-R.; methodology, R.A.-R., A.Z. and S.O.; investigation, A.Z. and S.O.; writing-Original draft preparation, A.Z.; writing-review and editing, R.A.-R., A.Z. and S.O.; supervision, R.A.-R.; project administration, A.Z. All authors have read and agreed to the published version of the manuscript.

Funding: This research received no external funding.

Institutional Review Board Statement: Not applicable.

Informed Consent Statement: Not applicable.

Data Availability Statement: The data presented in this study are available on request from the corresponding author.

Acknowledgments: We are grateful to the Ministry of Science, Technology, and Space for the fellowship of Ahmad Zarour.

Conflicts of Interest: The authors declare no conflict of interest.

\section{References}

1. Benaglia, M. Recoverable and Recyclable Catalysts; John Wiley \& Sons Ltd.: Hoboken, NJ, USA, 2009.

2. Hagen, J. Industrial Catalysis: A Practical Approach, 3rd ed.; Wiley-VCH Verlag GmbH \& Co. KGaA: Weinheim, Germany, 2015.

3. Cole-Hamilton, D.J. Homogeneous Catalysis-New Approaches to Catalyst Separation, Recovery, and Recycling. Science 2003, 299, 1702. [CrossRef]

4. van Leeuwen, P.W.N.M. Homogeneous Catalysis: Understanding the Art; Springer: Berlin/Heidelberg, Germany, 2004.

5. Friend, C.M.; Xu, B. Heterogeneous catalysis: A central science for a sustainable future. Acc. Chem. Res. 2017, 50, 517-521. [CrossRef]

6. Schlögl, R. Heterogeneous catalysis. Angew. Chem. Int. Ed. 2015, 54, 3465-3520. [CrossRef]

7. Yang, X.; Wang, Y.; Bai, R.; Ma, H.; Wang, W.; Sun, H.; Dong, Y.; Qu, F.; Tang, Q.; Guo, T.; et al. Pickering emulsion-enhanced interfacial biocatalysis: Tailored alginate microparticles act as particulate emulsifier and enzyme carrier. Green Chem. 2019, 21, 2229-2233. [CrossRef]

8. Zhang, Y.; Zhang, M.; Yang, H. Tuning biphasic catalysis reaction with a pickering emulsion strategy exemplified by selective hydrogenation of benzene. ChemCatChem 2018, 10, 5224-5230. [CrossRef]

9. Chen, Z.; Vorobyeva, E.; Mitchell, S.; Fako, E.; Ortuño, M.A.; López, N.; Collins, S.M.; Midgley, P.A.; Richard, S.; Vilé, G.; et al. A heterogeneous single-atom palladium catalyst surpassing homogeneous systems for suzuki coupling. Nat. Nanotechnol. 2018, 13, 702-707. [CrossRef] [PubMed]

10. Gross, E.; Somorjai, G.A. Mesoscale nanostructures as a bridge between homogeneous and heterogeneous catalysis. Top. Catal. 2014, 57, 812-821. [CrossRef]

11. Fadhel, A.Z.; Pollet, P.; Liotta, C.L.; Eckert, C.A. Combining the benefits of homogeneous and heterogeneous catalysis with tunable solvents and nearcritical water. Molecules 2010, 15, 8400-8424. [CrossRef]

12. Astruc, D.; Lu, F.; Aranzaes, J.R. Nanoparticles as recyclable catalysts: The Frontier between Homogeneous and Heterogeneous Catalysis. Angew. Chem. Int. Ed. 2005, 44, 7852-7872. [CrossRef] 
13. Polshettiwar, V.; Varma, R.S. Green chemistry by nano-catalysis. Green Chem. 2010, 12, 743-754. [CrossRef]

14. Benaglia, M.; Puglisi, A.; Cozzi, F. Polymer-supported organic catalysts. Chem. Rev. 2003, 103, 3401-3430. [CrossRef] [PubMed]

15. Lu, J.; Toy, P.H. Organic polymer supports for synthesis and for reagent and catalyst immobilization. Chem. Rev. 2009, 109, 815-838. [CrossRef]

16. Sun, Q.; Dai, Z.; Liu, X.; Sheng, N.; Deng, F.; Meng, X.; Xiao, F.-S. Highly efficient heterogeneous hydroformylation over rh-metalated porous organic polymers: Synergistic effect of high ligand concentration and flexible framework. J. Am. Chem. Soc. 2015, 137, 5204-5209. [CrossRef]

17. Bourque, S.C.; Maltais, F.; Xiao, W.-J.; Tardif, O.; Alper, H.; Arya, P.; Manzer, L.E. Hydroformylation reactions with rhodiumcomplexed dendrimers on silica. J. Am. Chem. Soc. 1999, 121, 3035-3038. [CrossRef]

18. Karakhanov, E.A.; Maximov, A.L.; Zolotukhina, A.V.; Yatmanova, N.; Rosenberg, E. Alkyne hydrogenation using Pd-Ag hybrid nanocatalysts in surface-immobilized dendrimers. Appl. Organomet. Chem. 2015, 29, 777-784. [CrossRef]

19. Ropartz, L.; Morris, R.E.; Cole-Hamilton, D.J.; Foster, D.F. Increased selectivity in hydroformylation reactions using dendrimer based catalysts; a positive dendrimer effect. Chem. Commun. 2001, 361-362. [CrossRef]

20. Haumann, M.; Jakuttis, M.; Werner, S.; Wasserscheid, P. Supported ionic liquid phase (SILP) catalyzed hydroformylation of 1-butene in a gradient-free loop reactor. J. Catal. 2009, 263, 321-327. [CrossRef]

21. Lou, L.-L.; Yu, K.; Ding, F.; Peng, X.; Dong, M.; Zhang, C.; Liu, S. Covalently anchored chiral Mn(III) salen-containing ionic species on mesoporous materials as effective catalysts for asymmetric epoxidation of unfunctionalized olefins. J. Catal. 2007, 249, 102-110. [CrossRef]

22. Mehnert, C.P.; Cook, R.A.; Dispenziere, N.C.; Afeworki, M. Supported ionic liquid catalysis-A new concept for homogeneous hydroformylation catalysis. J. Am. Chem. Soc. 2002, 124, 12932-12933. [CrossRef]

23. Batarseh, C.; Weiss, E.; Abu-Reziq, R. Metal nanoparticles supported on magnetically separable materials. In Nanotechnology in Catalysis; Springer: Berlin/Heidelberg, Germany, 2003; pp. 179-208.

24. Shaikh, M.N.; Aziz, M.A.; Helal, A.; Bououdina, M.; Yamani, Z.H.; Kim, T.-J. Magnetic nanoparticle-supported ferrocenylphosphine: A reusable catalyst for hydroformylation of alkene and mizoroki-heck olefination. RSC Adv. 2016, 6, 41687-41695. [CrossRef]

25. Shylesh, S.; Schünemann, V.; Thiel, W.R. Magnetically separable nanocatalysts: Bridges between homogeneous and heterogeneous catalysis. Angew. Chem. Int. Ed. 2010, 49, 3428-3459. [CrossRef]

26. Corma, A.; Garcia, H. Silica-bound homogenous catalysts as recoverable and reusable catalysts in organic synthesis. Adv. Synth. Catal. 2006, 348, 1391-1412. [CrossRef]

27. Mévellec, V.; Nowicki, A.; Roucoux, A.; Dujardin, C.; Granger, P.; Payen, E.; Philippot, K. A simple and reproducible method for the synthesis of silica-supported rhodium nanoparticles and their investigation in the hydrogenation of aromatic compounds. New J. Chem. 2006, 30, 1214-1219. [CrossRef]

28. Sandee, A.J.; Reek, J.N.H.; Kamer, P.C.J.; van Leeuwen, P.W.N.M. A silica-supported, switchable, and recyclable hydroformylationhydrogenation catalyst. J. Am. Chem. Soc. 2001, 123, 8468-8476. [CrossRef] [PubMed]

29. Horecha, M.; Kaul, E.; Horechyy, A.; Stamm, M. Polymer microcapsules loaded with Ag nanocatalyst as active microreactors. J. Mater. Chem. A 2014, 2, 7431-7438. [CrossRef]

30. Meng, Z.; Zhang, M.; Yang, H. Pickering emulsion droplets hosting ionic liquid catalysts for continuous-flow cyanosilylation reaction. Green Chem. 2019, 21, 627-633. [CrossRef]

31. Price, K.E.; Mason, B.P.; Bogdan, A.R.; Broadwater, S.J.; Steinbacher, J.L.; McQuade, D.T. Microencapsulated Linear polymers: "soluble" heterogeneous catalysts. J. Am. Chem. Soc. 2006, 128, 10376-10377. [CrossRef]

32. Wu, C.; Bai, S.; Ansorge-Schumacher, M.B.; Wang, D. Nanoparticle cages for enzyme catalysis in organic media. Adv. Mater. 2011, 23, 5694-5699. [CrossRef]

33. Zhang, X.; Hou, Y.; Ettelaie, R.; Guan, R.; Zhang, M.; Zhang, Y.; Yang, H. Pickering emulsion-derived liquid-solid hybrid catalyst for bridging homogeneous and heterogeneous catalysis. J. Am. Chem. Soc. 2019, 141, 5220-5230. [CrossRef]

34. Zhou, X.; Chen, C.; Cao, C.; Song, T.; Yang, H.; Song, W. Enhancing reaction rate in a pickering emulsion system with natural magnetotactic bacteria as nanoscale magnetic stirring bars. Chem. Sci. 2018, 9, 2575-2580. [CrossRef]

35. Benita, S. Microencapsulation: Methods and Industrial Applications, 2nd ed.; Drugs and Pharmaceutical Sciences; Taylor \& Francis: New Delhi, India, 2006; Volume 158, 756p.

36. Dubey, R.; Shami, T.C.; Rao, K.U.B. Microencapsulation technology and applications. Def. Sci. J. 2009, $59,82-95$.

37. Jyothi, N.V.N.; Prasanna, P.M.; Sakarkar, S.N.; Prabha, K.S.; Ramaiah, P.S.; Srawan, G.Y. Microencapsulation techniques, factors influencing encapsulation efficiency. J. Microencapsul. 2010, 27, 187-197. [CrossRef]

38. Oh Seok, K.; Jyongsik, J.; Joonwon, B. A review of fabrication methods and applications of novel tailored microcapsules. Curr. Org. Chem. 2013, 17, 3-13. [CrossRef]

39. Li, T.; Teng, D.; Mao, R.; Hao, Y.; Wang, X.; Wang, J. Recent progress in preparation and agricultural application of microcapsules. J. Biomed. Mater. Res. A 2019, 107, 2371-2385. [CrossRef]

40. Michaelakis, A.; Mihou, A.P.; Koliopoulos, G.; Couladouros, E.A. Attract-and-kill strategy. Laboratory studies on hatched larvae of culex pipiens. Pest. Manag. Sci. 2007, 63, 954-959. [CrossRef]

41. Scarfato, P.; Avallone, E.; Iannelli, P.; De Feo, V.; Acierno, D. Synthesis and characterization of polyurea microcapsules containing essential oils with antigerminative activity. J. Appl. Polym. Sci. 2007, 105, 3568-3577. [CrossRef] 
42. Sharpe, L.A.; Vela Ramirez, J.E.; Haddadin, O.M.; Ross, K.A.; Narasimhan, B.; Peppas, N.A. pH-responsive microencapsulation systems for the oral delivery of polyanhydride nanoparticles. Biomacromolecules 2018, 19, 793-802. [CrossRef] [PubMed]

43. Singh, M.N.; Hemant, K.S.Y.; Ram, M.; Shivakumar, H.G. Microencapsulation: A promising technique for controlled drug delivery. Res. Pharm. Sci. 2010, 5, 65-77. [PubMed]

44. Sanz-Ruiz, P.; Carbo-Laso, E.; Del Real-Romero, J.C.; Aran-Ais, F.; Ballesteros-Iglesias, Y.; Paz-Jimenez, E.; Sanchez-Navarro, M.; Perez-Liminana, M.A.; Vaquero-Martin, J. Microencapsulation of rifampicin: A technique to preserve the mechanical properties of bone cement. J. Orthop. Res. 2018, 36, 459-466. [CrossRef] [PubMed]

45. Jackson, L.; Lee, K. Microencapsulation in the food industry. LWT Food Sci. Technol. 1991, 24, $289-297$.

46. Nedovic, V.; Kalusevic, A.; Manojlovic, V.; Levic, S.; Bugarski, B. An overview of encapsulation technologies for food applications. Procedia Food Sci. 2011, 1, 1806-1815. [CrossRef]

47. Sohi, H.; Sultana, Y.; Khar, R.K. Taste masking technologies in oral pharmaceuticals: Recent developments and approaches. Drug Dev. Ind. Pharm. 2004, 30, 429-448. [CrossRef] [PubMed]

48. Guan, Z.; Hu, J.; Gu, Y.; Zhang, H.; Li, G.; Li, T. PdCl2(py)2 encaged in monodispersed zeolitic hollow spheres: A highly efficient and reusable catalyst for Suzuki-Miyaura cross-coupling reaction in aqueous media. Green Chem. 2012, 14, 1964-1970. [CrossRef]

49. Zhu, W.; Chen, Z.; Pan, Y.; Dai, R.; Wu, Y.; Zhuang, Z.; Wang, D.; Peng, Q.; Chen, C.; Li, Y. Functionalization of hollow nanomaterials for catalytic applications: Nanoreactor construction. Adv. Mater. 2019, 31, 1800426. [CrossRef] [PubMed]

50. Akiyama, R.; Kobayashi, S. "Microencapsulated" and related catalysts for organic chemistry and organic synthesis. Chem. Rev. 2009, 109, 594-642. [CrossRef]

51. Prieto, G.; Tüysüz, H.; Duyckaerts, N.; Knossalla, J.; Wang, G.-H.; Schüth, F. Hollow nano- and microstructures as catalysts. Chem. Rev. 2016, 116, 14056-14119. [CrossRef]

52. Samanta, B.; Yang, X.-C.; Ofir, Y.; Park, M.-H.; Patra, D.; Agasti, S.S.; Miranda, O.R.; Mo, Z.-H.; Rotello, V.M. Catalytic microcapsules assembled from enzyme-Nanoparticle conjugates at oil-water interfaces. Angew. Chem. Int. Ed. 2009, 48, 5341-5344. [CrossRef]

53. Song, Y.; Fan, J.-B.; Wang, S. Recent progress in interfacial polymerization. Mater. Chem. Front. 2017, 1, 1028-1040. [CrossRef]

54. Zhang, Y.; Rochefort, D. Characterisation and applications of microcapsules obtained by interfacial polycondensation. J. Microencapsul. 2012, 29, 636-649. [CrossRef]

55. Perignon, C.; Ongmayeb, G.; Neufeld, R.; Frere, Y.; Poncelet, D. Microencapsulation by interfacial polymerisation: Membrane formation and structure. J. Microencapsul. 2015, 32, 1-15. [CrossRef]

56. Raaijmakers, M.J.T.; Benes, N.E. Current trends in interfacial polymerization chemistry. Prog. Polym. Sci. 2016, 63, 86-142. [CrossRef]

57. Yadav, S.K.; Khilar, K.C.; Suresh, A.K. Microencapsulation in polyurea shell: Kinetics and film structure. AlChE J. 1996, 42, 2616-2626. [CrossRef]

58. Hong, K.; Park, S. Polyurea microcapsules with different structures: Preparation and properties. J. Appl. Polym. Sci. 2000, 78, 894-898. [CrossRef]

59. Li, J.; Mazumder, M.A.J.; Stöver, H.D.H.; Hitchcock, A.P.; Shirley, I.M. Polyurea microcapsules: Surface modification and capsule size control. J. Polym. Sci. Part. A Polym. Chem. 2011, 49, 3038-3047. [CrossRef]

60. Brochu, A.B.W.; Chyan, W.J.; Reichert, W.M. Microencapsulation of 2-octylcyanoacrylate tissue adhesive for self-healing acrylic bone cement. J. Biomed. Mater. Res. B 2012, 100B, 1764-1772. [CrossRef]

61. Baier, G.; Friedemann, K.; Leuschner, E.-M.; Musyanovych, A.; Landfester, K. pH Stability of poly(urethane/urea) capsules synthesized from different hydrophilic monomers via interfacial polyaddition in the inverse miniemulsion process. Macromol. Symp. 2013, 331-332, 71-80. [CrossRef]

62. Natour, S.; Levi-Zada, A.; Abu-Reziq, R. Magnetic polyurea nano-capsules synthesized via interfacial polymerization in inverse nano-emulsion. Molecules 2019, 24, 2663. [CrossRef]

63. Morral-Ruíz, G.; Melgar-Lesmes, P.; García, M.L.; Solans, C.; García-Celma, M.J. Design of biocompatible surface-modified polyurethane and polyurea nanoparticles. Polymer 2012, 53, 6072-6080. [CrossRef]

64. Weiss, E.; Gertopski, D.; Gupta, M.K.; Abu-Reziq, R. Encapsulation of ionic liquid BMIm[PF6] within polyurea microspheres. React. Funct. Polym. 2015, 96, 32-38. [CrossRef]

65. Zhou, J.; Xu, W.; Wang, Y.-n.; Shi, B. Preparation of polyurea microcapsules containing phase change materials in a rotating packed bed. RSC Adv. 2017, 7, 21196-21204. [CrossRef]

66. Hedaoo, R.K.; Mahulikar, P.P.; Chaudhari, A.B.; Rajput, S.D.; Gite, V.V. Fabrication of core-shell novel polyurea microcapsules using isophorone diisocyanate (ipdi) trimer for release system. Int. J. Polym. Mater. Polym. Biomater. 2014, 63, 352-360. [CrossRef]

67. Polenz, I.; Datta, S.S.; Weitz, D.A. Controlling the morphology of polyurea microcapsules using microfluidics. Langmuir 2014, 30, 13405-13410. [CrossRef] [PubMed]

68. Zia, A.; Pentzer, E.; Thickett, S.; Kempe, K. Advances and opportunities of oil-in-oil emulsions. ACS Appl. Mater. Interfaces 2020, 12, 38845-38861. [CrossRef]

69. Binks, B.P.; Tyowua, A.T. Oil-in-oil emulsions stabilised solely by solid particles. Soft Matter 2016, 12, 876-887. [CrossRef]

70. Asano, I.; So, S.; Lodge, T.P. Oil-in-oil emulsions stabilized by asymmetric polymersomes formed by AC + BC block polymer co-assembly. J. Am. Chem. Soc. 2016, 138, 4714-4717. [CrossRef] [PubMed]

71. Asano, I.; So, S.; Lodge, T.P. Location and influence of added block copolymers on the droplet size in oil-in-oil emulsions. Langmuir 2015, 31, 7488-7495. [CrossRef] [PubMed] 
72. Klapper, M.; Nenov, S.; Haschick, R.; Müller, K.; Müllen, K. Oil-in-oil emulsions: A unique tool for the formation of polymer nanoparticles. Acc. Chem. Res. 2008, 41, 1190-1201. [CrossRef] [PubMed]

73. Arumugam, S.; Hughes, A.; Even, R.C. Microcapsules with Core-Shell Structure. U.S. Patent 20150231589A1, 20 August 2015.

74. Shukla, P.G.; Jadhav, A.S. Microcapsule Composition Containing Water-Soluble Amine and a Process for the Preparation Thereof. WO2016075708A1, 10 November 2015.

75. Shukla, P.G.; Jagtap, S.B.; Biradar, S.C.; Charpe, V.P.; Jadhav, A.S. Preparation and characterization of microcapsules containing industrially important reactive water-soluble polyamine. Colloid. Polym. Sci. 2016, 294, 2039-2050. [CrossRef]

76. Kobašlija, M.; McQuade, D.T. Polyurea Microcapsules from oil-in-oil emulsions via interfacial polymerization. Macromolecules 2006, 39, 6371-6375. [CrossRef]

77. Lu, X.; Katz, J.S.; Schmitt, A.K.; Moore, J.S. A robust oil-in-oil emulsion for the nonaqueous encapsulation of hydrophilic payloads. J. Am. Chem. Soc. 2018, 140, 3619-3625. [CrossRef] [PubMed]

78. Kainz, Q.M.; Linhardt, R.; Grass, R.N.; Vilé, G.; Pérez-Ramírez, J.; Stark, W.J.; Reiser, O. Palladium nanoparticles supported on magnetic carbon-coated cobalt nanobeads: Highly active and recyclable catalysts for alkene hydrogenation. Adv. Funct. Mater. 2014, 24, 2020-2027. [CrossRef]

79. Yamada, Y.M.A.; Yuyama, Y.; Sato, T.; Fujikawa, S.; Uozumi, Y. A palladium-nanoparticle and silicon-nanowire-array hybrid: A platform for catalytic heterogeneous reactions. Angew. Chem. Int. Ed. 2014, 53, 127-131. [CrossRef]

80. Nishikata, T.; Tsutsumi, H.; Gao, L.; Kojima, K.; Chikama, K.; Nagashima, H. Adhesive catalyst immobilization of palladium nanoparticles on cotton and filter paper: Applications to reusable catalysts for sequential catalytic reactions. Adv. Synth. Catal. 2014, 356, 951-960. [CrossRef]

81. Ley, S.V.; Ramarao, C.; Gordon, R.S.; Holmes, A.B.; Morrison, A.J.; McConvey, I.F.; Shirley, I.M.; Smith, S.C.; Smith, M.D. Polyurea-encapsulated palladium(ii) acetate: A robust and recyclable catalyst for use in conventional and supercritical media. Chem. Commun. 2002, 1134-1135. [CrossRef]

82. Ramarao, C.; Ley, S.V.; Smith, S.C.; Shirley, I.M.; DeAlmeida, N. Encapsulation of palladium in polyurea microcapsules. Chem. Commun. 2002, 1132-1133. [CrossRef]

83. Liu, Y.; Feng, X.; Bao, D.; Li, K.; Bao, M. A new method for the preparation of microcapsule-supported palladium catalyst for suzuki coupling reaction. J. Mol. Catal. A Chem. 2010, 323, 16-22. [CrossRef]

84. Ji, H.; Long, Q.; He, Y.; Yao, X. Palladium nanoclusters entrapped in polyurea: A recyclable and efficient catalyst for reduction of nitro-benzenes and hydrodechlorination of halogeno-benzenes. Sci. China Chem. 2010, 53, 1520-1524. [CrossRef]

85. Chen, J.; Spear, S.K.; Huddleston, J.G.; Rogers, R.D. Polyethylene glycol and solutions of polyethylene glycol as green reaction media. Green Chem. 2005, 7, 64-82. [CrossRef]

86. Mahou, R.; Wandrey, C. Versatile route to synthesize heterobifunctional poly(ethylene glycol) of variable functionality for subsequent pegylation. Polymers 2012, 4, 561-589. [CrossRef]

87. Hou, Z; Theyssen, N.; Leitner, W. Palladium nanoparticles stabilised on PEG-modified silica as catalysts for the aerobic alcohol oxidation in supercritical carbon dioxide. Green Chem. 2007, 9, 127-132. [CrossRef]

88. Huang, T.S.; Wang, Y.H.; Jiang, J.Y.; Jin, Z.L. PEG-stabilized palladium nanoparticles: An efficient and recyclable catalyst for the selective hydrogenation of 1,5-cyclooctadiene in thermoregulated PEG biphase system. Chin. Chem. Lett. 2008, 19, 102-104. [CrossRef]

89. Zhu, W.; Yang, H.; Yu, Y.; Hua, L.; Li, H.; Feng, B.; Hou, Z. Amphiphilic ionic liquid stabilizing palladium nanoparticles for highly efficient catalytic hydrogenation. Phys. Chem. Chem. Phys. 2011, 13, 13492-13500. [CrossRef] [PubMed]

90. Harraz, F.A.; El-Hout, S.E.; Killa, H.M.; Ibrahim, I.A. Palladium nanoparticles stabilized by polyethylene glycol: Efficient, recyclable catalyst for hydrogenation of styrene and nitrobenzene. J. Catal. 2012, 286, 184-192. [CrossRef]

91. Wang, R.; Kang, Y.; Lei, T.; Li, S.; Zhou, Z.; Xiao, Y. Microcapsules composed of stearic acid core and polyethylene glycol-based shell as a microcapsule phase change material. Int. J. Energy Res. 2021, 45, 9677-9684. [CrossRef]

92. Abdeali, G.; Abdollahi, M.; Bahramian, A.R. Synthesis and characterization of paraffin wax nanocapsules with polyurethane shell (PU/PW); the droplet size distribution: A key factor for thermal performance. Renew. Energy 2021, 163, 720-731. [CrossRef]

93. Leclercq, L.; Dechezelles, J.-F.; Rauwel, G.; Nardello-Rataj, V. In vitro study of versatile drug formulations based on $\alpha$-cyclodextrin and polyethylene glycol using colloidal tectonics. J. Drug Deliv. Sci. Technol. 2020, 59, 101913. [CrossRef]

94. Huang, D.; Sun, M.; Bu, Y.; Luo, F.; Lin, C.; Lin, Z.; Weng, Z.; Yang, F.; Wu, D. Microcapsule-embedded hydrogel patches for ultrasound responsive and enhanced transdermal delivery of diclofenac sodium. J. Mater. Chem. B 2019, 7, 2330-2337. [CrossRef]

95. Nam, C.; Yoon, J.; Ryu, S.A.; Choi, C.-H.; Lee, H. Water and oil insoluble pegda-based microcapsule: Biocompatible and multicomponent encapsulation. ACS Appl. Mater. Interfaces 2018, 10, 40366-40371. [CrossRef]

96. Pan, H.M.; Yu, H.; Guigas, G.; Fery, A.; Weiss, M.; Patzel, V.; Trau, D. Engineering and design of polymeric shells: Inwards interweaving polymers as multilayer nanofilm, immobilization matrix, or chromatography resins. ACS Appl. Mater. Interfaces 2017, 9, 5447-5456. [CrossRef] 